\title{
INNOVACIÓN Y TIC EN EL PAISAJE SONORO DE LA MÚSICA FESTERA A TRAVÉS DE LA CREACIÓN DE MUSICOMOVIGRAMAS
}

\section{Innovation and ICTs in the sound landscape of festive music through the creation of musicomovigrams}

\author{
Ina María Botella Nicolás: Universitat de València. España. \\ ana.maria.botella@uv.es
}

1 Amparo Hurtado Soler2: Universitat de València. España. amparo.hurtado@uv.es

Sonsoles Ramos Ahijado3: Universidad de Salamanca. España. sonsolesra@usal.es

Este trabajo está financiado por el proyecto de investigación I+D+i GV/2017/095: El paisaje sonoro, escucha, creación y recreación. Análisis de escenarios de educación ambiental y musical de la Conselleria d'Educació, Investigació, Cultura i Esport de la Generalitat Valenciana.

\section{RESUMEN}

Este artículo es parte de un proyecto de investigación sobre el paisaje sonoro, la escucha y la creación y recreación de espacios de educación ambiental y musical. Consiste en una propuesta de creación y utilización de un recurso auditivo-didáctico e interactivo, el musicomovigrama o musicograma en movimiento, para trabajar la escucha y el desarrollo emocional mediante la Fiesta y la música de Moros y Cristianos de Alcoy y su paisaje sonoro. La gran potencialidad de este recurso deriva de su capacidad para ofrecer al alumnado un soporte visual atractivo sincronizado con la progresión de la música que escucha, de tal manera que ambos códigos avancen simultáneamente. El objetivo principal es estudiar el paisaje sonoro y el entorno acústico, así como el medio natural y los sentidos, para incentivar la sensibilización auditiva en las aulas y fomentar

\footnotetext{
${ }^{1}$ Ana María Botella Nicolás: Doctora en Pedagogía. Profesora contratada doctora del Departamento de Didáctica de la Expresión Musical, Plástica y Corporal de la Facultad de Magisterio de la Universitat de València.

2 Amparo Hurtado Soler: Doctora en Biología. Profesora ayudante doctora del Dpto. de Didáctica de las Ciencias Experimentales y Sociales de la Facultad de Magisterio de la Universitat de València.

3 Sonsoles Ramos Ahijado: Doctora en Musicología. Profesora contratada doctorada del Dpto. de Didáctica de la Expresión Musical, Plástica y Corporal de la Escuela de Educación y Turismo de Ávila.
} 
Botella Nicolás, A. M., Hurtado Soler, A., y Ramos Ahijado, S. Innovación y TIC en el paisaje sonoro de la música festera a través de la creación de musicomovigramas

la escucha activa y consciente de los diferentes entornos o paisajes sonoros, favorables o perjudiciales. Los resultados demuestran que este tipo de aplicaciones permite desarrollar la percepción del entorno dentro del aula con aproximaciones quasi-reales incrementando la conexión entre la percepción natural del medio y la expresión artística. La utilización de las TIC como herramientas transversales permite profundizar en la composición del paisaje visual y sonoro relacionando los sonidos ambientales con los instrumentos y seleccionando estilos musicales con base en el paisaje.

PALABRAS CLAVE: innovación - TIC - paisaje sonoro - música festera musicomovigramas - escucha - educación ambiental.

\section{ABSTRACT}

This article is part of a research project on the sound landscape, listening and creation and recreation of environmental and musical education spaces. It consists in a proposal for the creation and use of an interactive auditory-didactic resource, the musicomovigram or musicogram in movement, to work with listening and emotional development through the Fiesta and the music of Moors and Christians of Alcoy and its sound landscape. The great potential of this resource derives from its ability to offer students an attractive visual support synchronized with the progression of the music they listen to, in such a way that both codes advance simultaneously. The main objective is to study the sound landscape and the acoustic environment, as well as the natural environment and the senses, to encourage auditory awareness in the classrooms and encourage active and conscious listening to different environments or sound landscapes, favorable or harmful. The results show that this type of applications makes it possible to develop the perception of the environment within the classroom with quasi - real approaches, increasing the connection between the natural perception of the medium and the artistic expression. The use of ICTs as transversal tools makes it possible to deepen the composition of the visual and sound landscape by relating the environmental sounds with the instruments and selecting musical styles based on the landscape.

KEY WORDS: innovation - ICTs - sound landscape - festival music musicomovigramas - listening - environmental education.

\section{INNOVAÇÃO E TIC NO ÂMBITO SONORO DA MÚSICA FESTEIRA ATRAVÉS DA CRIAÇÃO MUSICOMOVIGRAMAS}

\section{RESUME}

Este artigo é parte de um projeto de investigação sobre o âmbito sonoro, a escuta e a criação e recreação de espaços de educação ambiental e musical. Consiste em uma proposta de criação e utilização de um recurso auditivo - didático e interativo, o

Vivat Academia. Revista de Comunicación. 15 junio 2019 /15 septiembre 2019, nº 147, 109-123 
Botella Nicolás, A. M., Hurtado Soler, A., y Ramos Ahijado, S. Innovación y TIC en el paisaje sonoro de la música festera a través de la creación de musicomovigramas

musicomovigrama ou musicograma em movimento, para trabalhar a escuta e o desenvolvimento emocional mediante a Festa e a música de Moros e Cristianos de Alcoy e seu âmbito sonoro. A grande potencialidade de este recurso deriva de sua capacidade para oferecer ao aluno um suporte visual atrativo sincronizado com a progressão da música que escuta, de tal maneira que ambos códigos avancem simultaneamente. $\mathrm{O}$ objetivo principal é estudar o âmbito sonoro e o entorno acústico, assim como o meio natural e os sentidos, para incentivar a sensibilização auditiva nas aulas e fomentar a escuta ativa e consciente dos diferentes entornos favoráveis ou prejudiciais. Os resultados demonstram que este tipo de aplicações permite desenvolver a percepção do entorno dentro da aula com aproximações quase reais incrementando a conexão entre a percepção natural do meio e a expressão artística. A utilização de TIC como ferramentas transversais permite aprofundar na composição visual e sonoro relacionando os sons ambientais com os instrumentos e selecionando estilos musicais com base neste âmbito.

PALAVRAS CHAVE: inovação - TIC - ãmbito sonoro - música festeira musicomovigramas - escutar - educação ambiental.

\section{Como citar el artículo:}

Botella Nicolás, A. M., Hurtado Soler, A., y Ramos Ahijado, S. (2019). Innovación y TIC en el paisaje sonoro de la música festera a través de la creación de musicomovigramas. [Innovation and ICTs in the sound landscape of festive music through the creation of musicomovigrams]. Vivat Academia. Revista de Comunicación, 147, 109-123. http://doi.org/10.15178/va.2019.147.109-123. Recuperado de http://www.vivatacademia.net/index.php/vivat/article/view/1125

\section{INTRODUCCIÓN}

La Fiesta de Moros y Cristianos constituye una de las tradiciones culturales más arraigadas en todo el levante español. Esta fiesta genera su propia música, la festera, que es una gran aportación que ha enriquecido el repertorio original bandístico al mismo tiempo que tiene unos contenidos propios que le confieren carácter y la distinguen de cualquier otro género musical. Sus tres formas musicales para el desfile son la marcha mora, la cristiana y el pasodoble (Botella, 2012; Botella y Hurtado, 2017). Estas piezas constituyen un caudal musical y didáctico de primer orden para trabajar contenidos curriculares transversales de la misma manera que lo hacemos con la música clásica, contribuyendo así al desarrollo de actitudes favorecedoras del desarrollo personal y colectivo, así como del aprendizaje desde una visión holística y vivencial.

La música es sonido y como tal es percibida por los oídos contribuyendo al proceso de la formación musical a través de la técnica de escucha. Además puede utilizarse como herramienta potenciadora de la atención, la observación, el análisis y el desarrollo emocional y sensorial (Botella y Hurtado, 2016). La Fiesta de Moros y Cristianos es un 
Botella Nicolás, A. M., Hurtado Soler, A., y Ramos Ahijado, S. Innovación y TIC en el paisaje sonoro de la música festera a través de la creación de musicomovigramas

escenario idóneo para trabajar la escucha y de este modo percibir el paisaje a través de los sentidos.

De acuerdo con el Convenio Europeo del Paisaje, éste es cualquier parte del territorio, tal como es percibida por las poblaciones cuyo carácter resulta de la acción de factores naturales y/o humanos y de sus interrelaciones. En consecuencia, la concepción del paisaje debe integrar las siguientes dimensiones: a) Perceptiva, considerando no sólo la percepción visual sino la del conjunto de los sentidos; b) Natural, con factores tales como suelo, agua, vegetación, fauna, aire, en todas sus manifestaciones, estado y valor; c) Humana, que incluye al hombre, sus relaciones sociales, su actividad económica y su acervo cultural y d) Temporal, entendiendo que las dimensiones perceptiva, natural y humana no tienen carácter estático, sino que evolucionan a corto, medio y largo plazo. Todas las ciencias se nutren del paisaje. El paisaje es fuente de conocimiento interdisciplinar y cotidiano que envuelve al ser humano a lo largo de su existencia y condiciona su vida al tiempo que es modelado por la acción humana, es decir, el paisaje como patrimonio cultural, artístico y natural (Botella y Hurtado, 2017).

El compositor y pedagogo canadiense R. Murray Schafer (1933-) acuña el concepto de entorno o paisaje sonoro $(1969,1972,1975)$ a mediados de los años 70 con interesantes aplicaciones en el análisis musical y en la composición, pero también con implicaciones notables en el campo ecológico y pedagógico. Schafer construye la representación del medio ambiente sonoro como si fuera una composición musical (Carles, 2007). El término es la unión de las palabras sound (sonido) y landscape (paisaje) formando la palabra soundscape. Sobre esta idea se explica cómo se puede distinguir y estudiar el universo sonoro que nos rodea. Es "básicamente un ambiente sonoro y puede referirse a entornos naturales o urbanos reales, o a construcciones abstractas -composiciones musicales, montajes analógicos o digitales que se presentan como ambientes sonoros-" (Delgado, 2015, p. 121). En estos términos, el paisaje debe considerarse, tal y como explica Gómez (2010, p. 91), "como un hecho de interés general, como patrimonio ambiental, cultural y productivo, y como una fuente inagotable de conocimiento en constante transformación que demanda cada vez mayor compromiso social".

Por tanto, el objetivo general de esta propuesta es recrear el paisaje sonoro de la música festera como estrategia para la educación ambiental y musical a través de la escucha mediante la creación de musicomovigramas. En lo que a la enseñanza musical se refiere, ésta se centra en la percepción y la expresión (Ballesteros y García, 2010). La primera de ellas está basada en la audición y puede trabajarse a través de cuentos, canciones y obras clásicas. La segunda incluye el canto, la danza, el movimiento y la práctica instrumental. La música, a través de las experiencias sensoriales que proporciona, enriquece y dota a los niños y las niñas de un equilibrio psicofisiológico, emocional y social (Sarget, 2003). Las actividades musicales, permiten el desarrollo de multitud de capacidades tales como: desarrollo de la memoria, participación, sentido de

Vivat Academia. Revista de Comunicación. 15 junio 2019 /15 septiembre 2019, nº 147, 109-123 
Botella Nicolás, A. M., Hurtado Soler, A., y Ramos Ahijado, S. Innovación y TIC en el paisaje sonoro de la música festera a través de la creación de musicomovigramas

grupo o discriminación auditiva. En este sentido, Caprav (2003) y Reynoso (2010), citados por Díaz, Díaz y Morales (2014), afirman que al encontrarnos en un mundo totalmente sonoro, la educación a través de la música se considera uno de los pilares fundamentales en el desarrollo integral del ser humano. Es decir, la música provoca una reacción entre los procesos físicos y psicológicos que permiten el desarrollo de habilidades como son: la audición, la relación espacial, la motricidad fina, el ritmo, la lateralidad o la concentración.

Es importante señalar que la música posee una serie de características auditivosensoriales que actúan sobre las diferentes partes del cerebro. Por una parte, las audiciones rítmicas se encuentran situadas en la parte del cerebro en que tienen lugar las acciones motrices y dinámicas. Las audiciones de obras melódicas están en el lugar donde se producen las emociones y los sentimientos. Finalmente, en las audiciones armónicas necesitan que se produzca una actividad intelectual más intensa y, por tanto, tienen lugar posteriormente. Estudios recientes atestiguan cómo la percepción sensorial del paisaje sonoro establece una estrecha relación entre la música y la salud emocional que facilita el desarrollo cognitivo y de la inteligencia emocional (Botella y Montesinos, 2016; Botella, Canet y Fosati, 2015 y 2017).

La audición es un eje fundamental en la enseñanza de la música, junto con el conocimiento teórico del lenguaje musical, la interpretación instrumental y vocal, y la danza o el movimiento. Gracias a la audición activa y comprensiva, el alumno se aproximará al mundo fascinante de la música. Por tanto, hay que convertirla en una práctica habitual y no en algo aislado. Con la audición potenciaremos sus habilidades de atención y concentración al mismo tiempo que haremos una limpieza de oído y educaremos el sentido el ritmo. Percibir y sentir el paisaje forma parte de un aprendizaje vivencial y experimental que se logra a través de la atención y de la concentración. De esta forma, la audición se convierte en una herramienta poderosa para trabajar la percepción sensorial del paisaje, mediante la creación de experiencias emocionales que favorecen la comprensión del medio natural y su relación con la expresión artística y emocional. Este pensamiento enlaza con la opinión de Benítez (2015) cuando expresa que:

El paisaje sonoro genera la posibilidad de la construcción de vías de preservación, reapropiación y concienciación del entorno partiendo de un proyecto de sensibilización, observación, análisis y diagnóstico que aporta estrategias metodológicas para entender la actividad sonora en las transformaciones que se realizan en nuestro territorio (p. 26).

\section{METODOLOGÍA}

Mediante la elaboración de musicomovigramas se recrea el paisaje sonoro de la Fiesta de Moros y Cristianos para percibir su esencia cultural y ambiental a través de la 
Botella Nicolás, A. M., Hurtado Soler, A., y Ramos Ahijado, S. Innovación y TIC en el paisaje sonoro de la música festera a través de la creación de musicomovigramas

escucha y la limpieza de oídos. De esta forma se identifican los elementos del paisaje y se relacionan con los elementos musicales, analizando las emociones y los efectos del sonido sobre la salud y el medio ambiente. Para alcanzar este objetivo utilizaremos los siguientes procedimientos metodológicos relacionados directamente con la estructura del proyecto:

1. Análisis de la percepción sensorial del paisaje a través de la escucha. En el eje de la percepción se llevan a cabo propuestas de escucha de los múltiples paisajes sonoros del recorrido de la Fiesta de Moros y Cristianos reconociendo los diversos escenarios urbanos y/o naturales en los que se desarrollan los desfiles. Se describen los elementos de cada paisaje, los sonidos y ambientes sonoros escuchados y se elabora un material de campo para la realización de la escucha.

2. Creación y producción de escenarios de paisaje sonoro virtual mediante TIC que se utilizan como herramientas transversales para trabajar los contenidos de las materias implicadas. Al mismo tiempo, permiten llevar al aula el medio físico y real y crear experiencias para conocer y profundizar en los elementos y la composición del paisaje visual y sonoro incluso generando escenarios no reales o distorsionado a partir de la realidad (cambiar los sonidos, introducir nuevos sonidos, crear sonidos mediante instrumentos que representen los sonidos naturales...).

3. A partir de los elementos y sonidos identificados se realizan musicomovigramas que expresen la relación entre el paisaje, los sonidos naturales y ambientales y la creación musical. Estos recursos consisten en documentos audiovisuales en los que la música aparece sincronizada con un determinado movimiento gráfico que representa alguno de los elementos que se quieran trabajar durante la audición, como la estructura, el pulso o el timbre, entre otros.

El estudio del paisaje sonoro se aplica en la formación del profesorado. Los participantes del estudio son 55 maestros en formación, de $4^{\circ}$ curso del Grado de Maestro de Primaria de la Universitat de València.

\section{PROPUESTA DE INNOVACIÓN}

Actualmente existe un conocimiento generalizado de la necesidad adecuar el sistema educativo a las exigencias sociales, para lo cual resulta inevitable introducir habitualmente procesos de reforma e innovación educativa. Estamos en un proceso que supone un cambio notable en la renovación de los contenidos y en la organización del sistema educativo (Díaz, Pascual, San Fabián Martínez, 1996). Las nuevas tecnologías han cambiado las formas de aprendizaje y priman, ante todo, la percepción visual por medio de la presentación de imágenes que van a gran velocidad (Ogalde y González, 2008). Efectuar estas acciones implica el desarrollo de habilidades específicas. Las instituciones educativas deben tomar conciencia de estas nuevas formas de promover el aprendizaje para incorporarlas a sus modelos de manera efectiva. Por ello, es importante

Vivat Academia. Revista de Comunicación. 15 junio 2019 /15 septiembre 2019, nº 147, 109-123 
Botella Nicolás, A. M., Hurtado Soler, A., y Ramos Ahijado, S. Innovación y TIC en el paisaje sonoro de la música festera a través de la creación de musicomovigramas

que tomemos conciencia de lo que las Reformas Educativas implican, no para permanecer en la denuncia de lo que no sirve, ni para añadir críticas, que en lugar de construir, destruyen los propósitos de progreso y desarrollo (Margaleff y Arenas, 2006).

Innovar en el quehacer docente motiva al profesor porque le hace sentirse actualizado y le mantiene al día buscando nuevas formas de enseñar. Así, conseguiremos mantener el interés por la materia, ofreciendo a las nuevas generaciones los conocimientos acorde a las necesidades actuales del campo profesional. Además, es fundamental proporcionar una especial atención a aspectos como la formación del profesorado, las condiciones, el número de profesores por aula, así como su organización, entre otros. Todo ello sin olvidar que las características del actual alumnado requiere una respuesta educativa muy exigente y difícil de llevar a cabo. La innovación implica un esfuerzo profesional como docente, a fin de que el alumno tenga una experiencia de aprendizaje, donde la interacción con los contenidos lo dirija a desarrollar habilidades como el razonamiento, el análisis de la información y la organización e integración con los demás.

La metodología de audición musical activa con el musicograma fue propuesta en la década de los años 70 por el pedagogo belga Jos Wuytack (1935-) para enseñar a escuchar música clásica a niños y jóvenes sin conocimientos musicales. Este sistema necesita la participación física y mental del oyente antes y durante la audición y también utiliza la percepción visual (el musicograma) para mejorar la percepción musical (Wuytack y Boal, 2009). Fue un recurso muy utilizado por el profesorado en la década de los 90 cuando la LOGSE crea un espacio musical en la escuela. Los musicogramas se generalizan en el contexto español y proliferan gracias al uso de determinadas metodologías musicales activas (Orff, Kodály, Willems o Dalcroze...). En realidad son registros gráficos de los acontecimientos musicales, es decir, una representación visual del desarrollo dinámico de una obra musical. La notación musical es substituida por un simbolismo ayudando así a la percepción total de la obra.

En las últimas décadas el musicograma ha ido evolucionando hasta el musicomovigrama, término acuñado por Honorato (2001) que lo definió como "la representación gráfica de la partitura musical mediante dibujo animado, muy pegado a la estructura musical y transparente en su comprensión para el niño que de esta manera capta en un sólo golpe intuitivo el significado de la música" (pp. 2-3). Los dos ejes teóricos básicos sobre los que se sustenta el estudio de los musicomovigramas son, por una parte, la didáctica de la audición musical y el desarrollo evolutivo del propio recurso en el marco de la incorporación de las TIC. Con los nuevos avances tecnológicos, existe la necesidad de dotar de un nuevo sentido a los musicogramas, adaptándolos a los tiempos contemporáneos, y por tanto, a los medios audiovisuales. Surgen así los musicomovigramas (Honorato, 2001; Botella y Marín, 2016a; Ramos y Botella, 2015), como un paso más en el estudio de la audición activa y reflexiva con musicogramas (Wuytack y Boal, 2009) o representación gráfica de la música. Constituyen un recurso

Vivat Academia. Revista de Comunicación. 15 junio 2019 /15 septiembre 2019, nº 147, 109-123 
Botella Nicolás, A. M., Hurtado Soler, A., y Ramos Ahijado, S. Innovación y TIC en el paisaje sonoro de la música festera a través de la creación de musicomovigramas

audiovisual en movimiento que las TIC lo convierten en idóneo para trabajar contenidos musicales desde un punto de vista comprensivo y cognitivo. Su gran potencialidad deriva de su capacidad para ofrecer al alumnado un soporte visual atractivo sincronizado con la progresión de la música que escucha, de tal manera que ambos códigos avancen simultáneamente.

Por otra parte, se han realizado distintas propuestas de aplicación de los musicomovigramas, integrándolos tanto en secuencias didácticas de educación musical (Botella y Marín, 2015, 2016b) como en la gamificación (Ramos y Botella, 2015). Del mismo modo, un estudio empírico demostró que los musicomovigramas facilitan el seguimiento de los musicogramas tradicionales y mejoran la motivación de los estudiantes, así como su capacidad de sostener la atención en el tiempo (Botella y Marín, 2016a).

Las propuestas diseñadas consisten en trabajar a través de escucha y de los musicomovigramas, creados ex profeso, cuestiones tanto formales como culturales y emocionales con piezas musicales vinculadas al repertorio festero de Alcoy ${ }^{4}$ y su paisaje sonoro. Un ejemplo lo constituye el musicomovigrama creado sobre la pieza L`Ambaixador Cristià de Rafael Mullor Grau donde el protagonismo melódico lo lleva la madera en diálogo constante con el metal. El hilo conductor y armónico corre a cargo de la percusión. Los alumnos desarrollan el sentido del ritmo al mismo tiempo que perciben el timbre de los instrumentos de viento madera y viento metal. Se ponen en práctica los planos de escucha que propone Copland (1955) para trabajar la audición. Por un lado, una escucha expresiva a través del movimiento y las primeras tomas de contacto. Por el otro, uno puramente musical, en el que el alumnado se fijará en los elementos más característicos que tiene la pieza, como la estructura binaria más la introducción y coda, los diferentes timbres instrumentales -sobre todo del viento madera y metal- o la intensidad del sonido. Y, finalmente, el plano emocional, donde la música de la fiesta descubre esas emociones mediante su escucha, relacionándolas con la representación y utilizándolas para trabajar la actitud, la motivación y la reflexión en relación a la cultura, el patrimonio y el medio sonoro. Para ello, los alumnos describen las sensaciones que sienten y asocian los instrumentos con los sonidos reales que descubren durante el recorrido por las calles y los parajes naturales donde se desarrollaron los hechos históricos. La percusión marca el ritmo de marcha cristiana y la melodía a cargo de la trompetería como es habitual en este tipo de composiciones cristianas. Los alumnos ajustan el tempo al ritmo de la marcha al mismo tiempo que discriminan las entradas de los instrumentos.

Los resultados muestran que este tipo de aplicaciones permite trabajar la percepción del entorno dentro del aula con aproximaciones quasi-reales incrementando la conexión

${ }^{4}$ La ciudad de Alcoy y su término municipal ocupan una extensión de 130,61 kilómetros cuadrados, implicando con ello que es el municipio más extenso de todos los que forman su comarca. Dentro de la Comunidad Valenciana, forma parte de la provincia de Alicante y es la capital de la comarca de L'Alcoià.

Vivat Academia. Revista de Comunicación. 15 junio 2019 /15 septiembre 2019, n 147, 109-123 
Botella Nicolás, A. M., Hurtado Soler, A., y Ramos Ahijado, S. Innovación y TIC en el paisaje sonoro de la música festera a través de la creación de musicomovigramas

entre la percepción natural del medio y la expresión artística al relacionar los sonidos naturales con los instrumentos y piezas musicales. En la relación entre el sonido del paisaje y el instrumento musical que mejor lo representa, la mayor parte del alumnado relaciona los sonidos propios de la naturaleza con instrumentos de cuerda (piano, arpa, violín) y viento (flauta, clarinete) mientras que los sonidos de origen humano se relacionan con instrumentos de percusión (tambor, batería) e instrumentos de viento como la trompeta.

Por otro lado, el análisis de los datos revela que el alumnado participante identifica mejor los elementos en la escena real que en la virtual, debido principalmente a las limitaciones técnicas y sensoriales de los dispositivos de grabación y edición.

En cuanto a la satisfacción e interés de la experiencia, más del 95\% reportan gran satisfacción y destacan la curiosidad, la virtualidad y el aspecto lúdico como características positivas de la actividad. Finalmente, destacan que los musicomovigramas son una herramienta que mejora la escucha ya que se eliminan los ruidos y se puede limpiar el ambiente acústico para mejorar la audición.

La experiencia presentada contribuye a la formación del profesorado en competencias digitales docentes en las cinco dimensiones: información, comunicación, creación de contenido, seguridad y solución de problemas ya que deben utilizar programas específicos para la creación y aplicación de los musicomovigramas. Entre las competencias desarrolladas por los participantes se distinguen las relacionadas con las competencias instrumentales: diseño y edición de la imagen digital, utilización de lenguaje audiovisual, uso educativo de la web 2.0; competencias didácticas: selección y evaluación objetiva de recursos educativos en soporte TIC, integración de los recursos TIC como instrumento, recurso y contenido didáctico; competencias organizativas y de elaboración de materiales didácticos.

\section{REFLEXIONES FINALES}

Actualmente a los profesores se les exige mejorar el rol tradicional y convertirse en profesionales del desarrollo, capaces de elaborar proyectos de innovación educativa para los alumnos de diversas edades, teniendo en consideración la realidad actual de las aulas en cuanto a la pluriculturalidad y diversidad del proceso enseñanza-aprendizaje. En esta línea es fundamental que los educadores adquieran múltiples competencias, para utilizarlas y actualizarlas en función de las circunstancias que se presentan en el aula con el paso del tiempo.

Integrar la cultura cotidiana facilita la comprensión y valorización de los conceptos y principios que el hombre utiliza en cada momento para vivir su propia realidad en el ámbito sociocultural al que pertenece. Ello permite contextualizar al alumno en un

Vivat Academia. Revista de Comunicación. 15 junio 2019 /15 septiembre 2019, nº 147, 109-123 
Botella Nicolás, A. M., Hurtado Soler, A., y Ramos Ahijado, S. Innovación y TIC en el paisaje sonoro de la música festera a través de la creación de musicomovigramas

proceso de aprendizaje que da lugar a la transferencia del conocimiento académico y, por tanto, alcanzar el propósito esencial de la educación que es incorporar al individuo a su medio con posibilidades de éxito, y de enriquecerlo y transformarlo. Para lograr una adecuada incorporación de la cultura cotidiana al currículo, el docente debe conocer los hábitos, los valores, los intereses y las costumbres de la comunidad. La incorporación de estos contenidos, destrezas y valores en el proceso de aprendizaje implica la adquisición de competencias de forma holística e integrada. Mediante simulaciones es posible recrear fenómenos y situaciones facilitando así la comprensión de sistemas complejos. Es evidente que las innovaciones aplicadas en el aula, revelan la reflexión sobre el quehacer diario docente en la búsqueda de la trasformación en el aula.

A partir de la percepción auditiva podemos investigar la relación música-paisajeemoción y generar materiales educativos que fomenten actitudes positivas y de valoración del paisaje incrementando la sensibilidad hacia su conservación, analizando los problemas de contaminación acústica y su influencia sobre la salud física y mental. La utilización de las TIC como herramientas transversales para trabajar los contenidos científicos y artístico-musicales permite profundizar en la composición del paisaje visual y sonoro relacionando los sonidos ambientales con los instrumentos y seleccionando estilos musicales con base en el paisaje. El medio natural es un contexto facilitador de la interdisciplinaridad que permite la sinergia entre disciplinas resolviendo problemas de la vida cotidiana. A partir de la experimentación, la indagación y la reflexión en el entorno se trabaja la relación entre la música y las ciencias estableciendo un feedback entre ambas que resulta muy interesante (Hurtado y Botella, 2016).

La utilización de los musicomovigramas como recurso didáctico presenta múltiples ventajas ya que ayuda a clarificar contenidos, incrementa la información relacionada con un tema concreto, promueve la observación y favorece la discusión y el debate. Por otra parte, los recursos audiovisuales proporcionan al alumno el control ya que puede adecuar su visualización según sus necesidades deteniendo o retrocediendo para optimizar su comprensión y asimilación. La composición de la música festera ofrece la oportunidad de relacionar la música y las situaciones que representa (batallas, entradas, desfiles...). De este modo nos aproximamos a la historia y la cultura. Pero más allá de lo evidente se encuentra la ocasión para descubrir las cualidades del sonido y cómo el ser humano lo percibe mediante el oído. Se produce una conexión entre el arte musical y la biología que permite relacionar la fisiología del oído con la transformación del sonido en nuestra mente para dar lugar a la música. Este conocimiento holístico genera una huella profunda en nuestro aprendizaje que perdurará toda la vida.

Mediante la implementación del proyecto de creación de musicomovigramas se han creado espacios de educación ambiental y musical donde estudiar el paisaje sonoro y el entorno acústico facilitando la sensibilización auditiva y el establecimiento de la conexión entre el entorno o paisaje con la música y las emociones. Los resultados 
Botella Nicolás, A. M., Hurtado Soler, A., y Ramos Ahijado, S. Innovación y TIC en el paisaje sonoro de la música festera a través de la creación de musicomovigramas

demuestran que este tipo de acciones desarrolla la percepción del medio y la expresión artística tomando como técnica la escucha y las TIC para profundizar en la composición del paisaje visual y sonoro.

La respuesta del alumnado participante ha sido muy positiva y han valorado su contribución en el aprendizaje ya que la percepción sensorial de la Fiesta de Moros y Cristianos a través de los musicomovigramas facilita la comprensión del entorno de forma globalizada e integral generando pensamiento crítico y socioconstructivo.

En conclusión, la utilización de los musicomovigramas y la escucha para trabajar el paisaje sonoro es una poderosa herramienta educativa para la formación holística del profesorado que contribuye al propósito esencial de la educación que es incorporar al individuo a su medio para fomentar las actitudes responsables y comprometidas y de este modo enriquecerlo y transformarlo desde sus competencias docentes, profesionales y ciudadanas.

\section{REFERENCIAS}

\section{Libros}

Copland, A. (1955). Cómo escuchar la música. Madrid: Fondo de cultura económica.

Díaz, M., Pascual, J., San Fabián, J. L., y Santiago Martínez, P. (1996). El desarrollo profesional docente y las resistencias a la innovación educativa. Servicio de Publicaciones. Universidad de Oviedo. Asturias.

Ogalde, I., y González, M. (2008). Nuevas tecnologías y educación: diseño, desarrollo, uso y evaluación de materiales didácticos. (No. Sirsi) i9789682481796.

Schafer, R. M. (1969). El nuevo paisaje sonoro. Canadá: Ricordi Americana.

Schafer, R. M. (1972). Limpieza de oídos. Buenos aires: Ricordi.

Schafer, R. M. (1975). El rinoceronte en el aula. Buenos aires: Ricordi.

\section{Capítulos de libro}

Botella, A. M., Canet, R. y Fosati, A. (2015). Inteligencia emocional y creativa mediante las artes visuales y la música: un estudio cualitativo en educación infantil. En III Congreso Internacional de Investigación e Innovación en educación infantil y Primaria, (pp. 
Botella Nicolás, A. M., Hurtado Soler, A., y Ramos Ahijado, S. Innovación y TIC en el paisaje sonoro de la música festera a través de la creación de musicomovigramas

247-259). Murcia: Editum. Recuperado de

https://www.academia.edu/21842174/Inteligencia_emocional_y_creativa_mediante las_artes_visuales_y_la_música_un_estudio_cualitativo_en_Educación_Infantil

Botella, A. y Marín, P. (2016b). El musicomovigrama como recurso didáctico para el desarrollo de la escucha. En E. Encabo (Ed.), Música y cultura audiovisual. De la pantalla al aula. (pp. 233-249). Murcia: Editum.

Botella, A. M. y Hurtado, A. (2017). El estudio del paisaje sonoro de la fiesta de moros y cristianos a través de la creación de musicomovigramas: desarrollo de la escucha y la salud emocional, en el $3^{\circ}$ Congreso Universitat de València -Institutos de Estudios Comarcales Medio ambiente y desarrollo territorial. (pp. 153-160). Valencia: Universitat de València. Recuperado de https://www.academia.edu/35100806/El_estudio_del_paisaje_sonoro_de_la_Fiesta_ de_Moros_y_Cristianos_a_través_de_la_creación_de_musicomovigramas_desarrollo de_la_escucha_y_la_salud_emocional

Carles, J. L. (2007). El paisaje sonoro, una herramienta interdisciplinar: análisis, creación y pedagogía con el sonido. En Centro Virtual Cervantes. Encuentro Iberoamericano sobre Paisajes Sonoros. Madrid.

Hurtado, A. y Botella, A. M. (2016). La interpretación del paisaje sonoro, una propuesta interdisciplinar para la formación del profesorado, en D. López, A. Escarbajal y T. Izdo (Eds.). Innovación y calidad en educación primaria, (pp. 124-134). Murcia: Editum.

Recuperado de https://www.academia.edu/33725678/La_interpretación_del_paisaje_sonoro._Una_ propuesta_interdisciplinar_para_la_formación_del_profesorado

Ramos, S. y Botella, A. M. (2015). Los videojuegos con musicomovigramas como recurso didáctico para la educación musical. En Congreso universitario internacional sobre la comunicación en la profesión y en la universidad de hoy: contenidos, investigación, innovación y docencia CUICIID, (p. 566). Madrid.

\section{Artículos}

Ballesteros, E. y García, M. (2010). Recursos didácticos para la enseñanza musical de 0 a 6 años. Revista LEEME, 26, 14-31. Recuperado de

http://musica.rediris.es/leeme/revista/ballesterosgarcia10.pdf

Botella, A. M. (2012). La creación musical en la Fiesta de moros y cristianos. Revista Música y Educación, 90, 60-83.

Vivat Academia. Revista de Comunicación. 15 junio 2019 /15 septiembre 2019, nº 147, 109-123 
Botella Nicolás, A. M., Hurtado Soler, A., y Ramos Ahijado, S. Innovación y TIC en el paisaje sonoro de la música festera a través de la creación de musicomovigramas

Botella, A. M. (2013). Amando Blanquer Ponsoda y su aportación al Concurso de Composición de Música Festera de Alcoy. Cuadernos de Música, Artes Visuales y Artes Escénicas, 8(2), 91-111. Recuperado de http://revistas.javeriana.edu.co/index.php/cma/article/viewFile/8202/6554

Botella, A. M. y Marín, P. (2016a). La utilización del musicomovigrama como recurso didáctico para el trabajo de la escucha atenta, comprensiva y activa en educación primaria. MAVAE. Cuadernos de Música, Artes Visuales y Artes Escénicas, 11(2), 213-235. Recuperado de http:/ / revistas.javeriana.edu.co/index.php/cma/article/view/15546/Art\%2012 doi: http://dx.doi.org/10.11144/Javeriana.mavae11-2.umrd

Botella, A. M., Canet, R. y Fosati, A. (2017). Desarrollo emocional y creativo en educación infantil mediante las artes visuales y la música. Revista CEIR, 1, 70-86.

Recuperado de https://www.academia.edu/35520581/Desarrollo_emocional_y_creativo_en_Educac ión_Infantil_mediante_las_artes_visuales_y_la_música

Delgado, E. (2015). El paisaje en la formación de maestros, un recurso educativo de alto interés para la educación primaria. TABANQUE: Revista pedagógica, 28, 117-138.

Gómez, A. (2010). El paisaje como patrimonio cultural, ambiental y productivo. Análisis e intervención para su sostenibilidad. KEPES, 7(6), 91-106. Recuperado de http://vip.ucaldas.edu.co/kepes/downloads/Revista6_6.pdf

Honorato, R. (2001). Trabajando con musicomovigramas. Revista LEEME, 8, 1-6. Recuperado de https://ojs.uv.es/index.php/LEEME/article/view/9727/9163

Margalef, L., y Arenas, A. (2006). ¿Qué entendemos por innovación educativa? A propósito del desarrollo curricular. Perspectiva Educacional, Formación de Profesores, 47, 13-31. Recuperado de https://www.redalyc.org/html/3333/333328828002/

Liana, M., Morales, R. y Díaz, W. (2014). La música como recurso pedagógico en la edad preescolar. Revista Infancias Imágenes, 13(1), 102-108. Recuperado de https://revistas.udistrital.edu.co/ojs/index.php/infancias/article/view/5455/9776

Sarget, Ma. A. (2003). La música en la Educación Infantil: estrategias cognitivomusicales. Ensayos: Revista de la Facultad de Educación de Albacete, 18, 197-209.

Recuperado de https://www.researchgate.net/publication/28154019_La_musica_en_la_educacion_i nfantil_Estrategias_cognitivo-musicales 
Botella Nicolás, A. M., Hurtado Soler, A., y Ramos Ahijado, S. Innovación y TIC en el paisaje sonoro de la música festera a través de la creación de musicomovigramas

Wuytack, J., y Boal, G. (2009). Audición activa con el musicograma. Eufonía. Didáctica de la Música, 47, 43-55.

\section{Trabajo fin de grado}

Benítez, J. (2015). El paisaje sonoro de algunos ambientes de la ciudad de Pereira como estrategia de educación ambiental. Trabajo de grado presentado como requisito parcial para optar al título de Administrador Ambiental. Universidad Tecnológica de Pereira. Recuperado de https://www.academia.edu/17865708/El_paisaje_Sonoro_de_algunos_ambientes_de_ la_ciudad_de_Pereira_como_estrategia_de_educación_ambiental

\section{AUTORAS}

\section{Ana María Botella Nicolás}

Doctora en pedagogía por la Universitat de València. Es Licenciada en Geografía e Historia, especialidad Musicología y maestra en Educación Musical, por la Universidad de Oviedo. Grado profesional en la especialidad de piano. Durante el año 2001 obtiene por oposición plaza en el cuerpo de profesores de música de enseñanza secundaria en Alicante (actualmente en excedencia). Ha presentado diversas comunicaciones en jornadas y congresos sobre didáctica de la música así como distintas publicaciones. Es profesora contratada doctora del departamento de didáctica de la Expresión Musical, Plástica y Corporal de la Facultad de Magisterio de la Universitat de València. Forma parte de la Comisión de Coordinación Académica del Master Universitario en Profesor/a de enseñanza secundaria de la UVEG y del Máster de Investigación en didácticas específicas. Desde Febrero de 2015 dirige el aula de música del Vicerrectorado de Cultura e Igualdad.

ana.maria.botella@uv.es

Orcid ID: 0000-0001-5324-7152

ResearchID: N-1375-2014

\section{Amparo Hurtado Soler}

Doctora en Biología. Profesora del Dpto. de Didáctica de las Ciencias Experimentales y sociales. Imparte docencia en las asignaturas de los itinerarios de Tecnologías de la información y comunicación (TIC) y Ciencias y matemáticas del grado de maestro de primaria, investigación básica en didáctica de las ciencias en el máster de didácticas específicas y tutorización del prácticum de magisterio. Dirección de TFM y TFG centrado en el uso de las TIC en educación y en la innovación educativa. Coordinadora del proyecto de innovación educativa L'Hort 2.0 integrado por 10 profesores de 6 áreas de conocimiento y 2 universidades. Líneas de investigación relacionadas con la salud y medioambiente, la innovación educativa y las TIC.

amparo.hurtado@uv.es 
Botella Nicolás, A. M., Hurtado Soler, A., y Ramos Ahijado, S. Innovación y TIC en el paisaje sonoro de la música festera a través de la creación de musicomovigramas

Orcid ID: 0000-0001-6627-2269

ResearchID: F-9762-2016

\section{Sonsoles Ramos Ahijado}

Doctora en Musicología por la Universidad de Salamanca. Licenciada en Historia y Ciencias de la Música. Diplomada en lengua extranjera: Francés y diplomada en Educación Musical. Profesora Contratada Doctora del Departamento de Didáctica de la Expresión Musical, Plástica y Corporal en la Universidad de Salamanca, impartiendo docencia en la Escuela Universitaria de Educación (Campus de Ávila), y en la Facultad de Educación de Salamanca. En la actualidad es subdirectora de docencia práctica en la Escuela Universitaria de Educación y Turismo de Ávila, coordinadora del Grado en Maestro en Educación Primaria y coordinadora de la especialidad de Música del Máster Universitario Profesional de Educación Secundaria Obligatoria y Bachillerato. sonsolesra@usal.es

Orcid ID: 0000-0002-8109-332X

ResearchID: H-7089-2018 